\title{
Complement C9 expression is associated with damaged myocardial cells in pediatric sudden death cases of fulminant myocarditis
}

Akari Takaya Uno ${ }^{1}$, Masahito Hitosugi ${ }^{1 *}$, Mami Nakamura ${ }^{1}$, Tomoyuki Nakanishi', Takahiro Mima² and Yoshihisa Higuchi

\begin{abstract}
Background: Because disease progression is so fast in sudden death of acute fulminant myocarditis, damage of myocardial cells is not evident in routine hematoxylin and eosin staining. To understand damage to myocardial cells and the mechanism of sudden death, immunohistochemical staining was performed for two forensic autopsy cases.

Case presentation: The patients were a healthy 5-year-old girl and 8-year-old boy. They suddenly died within 2 days of appearance of flu-like symptoms. An autopsy showed accumulation of yellowish-clear pericardial fluid containing fibrin deposits, fluid blood in the heart, and congestion of visceral organs. Histologically, minor necrosis or degeneration of myocardial cells with mainly lymphocytic infiltration was observed sometimes in tissue sections. Immunohistochemically, positive complement C9 staining and negative sirtuin 1 staining were found. These findings suggested wide damage of myocardial cells, even in regions with no marked changes in myocardial cells with hematoxylin and eosin staining. These areas corresponded to those with strong accumulation of lymphocytes.

Conclusions: Immunohistochemistry for complement C9 and sirtuin 1 might become a new tool for evaluating damage of myocardial cells of fulminant acute myocarditis.
\end{abstract}

Keywords: Autopsy, Case report, Child, Complement C9, Immunohistochemistry, Myocarditis, Sirtuin 1, Sudden death

\section{Background}

Acute myocarditis and fulminant myocarditis are relatively rare inflammatory diseases and can become a cause of sudden death (Matsuura et al. 2016). The mortality rate of fatal myocarditis is 0.46 per 10 million patients (Kamiyama 2016). Because the symptoms of myocarditis are widely distributed from mild flu-like symptoms to fatality, clinical diagnosis is difficult owing to its prompt progression (Fuse et al. 2000; Dancea 2001). Clinically,

\footnotetext{
* Correspondence: hitosugi@belle.shiga-med.ac.jp

'Department of Legal Medicine, Shiga University of Medical Science,

Tsukinowa, Seta, Otsu, Shiga 520-2192, Japan

Full list of author information is available at the end of the article
}

some cases lead to unexpected sudden death and are subsequently diagnosed at forensic autopsy. Diagnosis of myocarditis is based on histological evidence of an inflammatory infiltrate of myocardial cells with necrosis and/or degeneration of adjacent myocytes that is not typical for ischemic damage associated with coronary artery disease (Aretz et al. 1987). However, especially for fulminant cases, damage to myocardial cells is not evident in routine hematoxylin and eosin (HE) staining in some cases because progression of disease is so rapid. Therefore, understanding the mechanism of sudden cardiac death is difficult for these cases.

\section{Springer Open}

(c) The Author(s). 2020 Open Access This article is licensed under a Creative Commons Attribution 4.0 International License, which permits use, sharing, adaptation, distribution and reproduction in any medium or format, as long as you give appropriate credit to the original author(s) and the source, provide a link to the Creative Commons licence, and indicate if changes were made. The images or other third party material in this article are included in the article's Creative Commons licence, unless indicated otherwise in a credit line to the material. If material is not included in the article's Creative Commons licence and your intended use is not permitted by statutory regulation or exceeds the permitted use, you will need to obtain permission directly from the copyright holder. To view a copy of this licence, visit http://creativecommons.org/licenses/by/4.0/. 
We report two sudden deaths of children with acute fulminant myocarditis. Novel immunohistochemical methods clearly showed damaged myocardial cells. Our findings will help to understand progression of acute fulminant myocarditis in children.

\section{Case presentation}

\section{Case 1}

A healthy 5-year-old girl had suffered from mild abdominal pain with a body temperature of $38{ }^{\circ} \mathrm{C}$. The evening after her symptoms appeared, her appetite was lost and general fatigue increased. One day after the appearance of symptoms, she was transferred to a hospital because she was vomiting frequently. At arrival to the hospital, a blood examination showed a white blood cell count of $21,800 / \mu \mathrm{l}$ (normal range $4100-15,000 / \mu \mathrm{l}$ ), platelet count of $27.2 \times 10^{4} / \mu \mathrm{l}\left(18.0-51.0 \times 10^{4} / \mu \mathrm{l}\right)$, creatine kinase level of $135 \mathrm{U} / \mathrm{I}(46-230 \mathrm{U} / \mathrm{I})$, and C-reactive protein level of $3.2 \mathrm{mg} / \mathrm{dl}(>1.29 \mathrm{mg} / \mathrm{dl})$. A volume of $1000 \mathrm{ml}$ of fluid infusion with $10 \mathrm{mg}$ of metoclopramide improved her general condition, and she returned home. However, her general condition worsened again and frequent vomiting and abdominal pain appeared. Therefore, she was transferred to the hospital again. Before arriving at the hospital, she was in cardiopulmonary arrest. In spite of resuscitation attempts, she was pronounced dead 2 days after appearance of the initial symptoms. A forensic autopsy was performed the next day. Her height was 114 $\mathrm{cm}$ and weight was $18.6 \mathrm{~kg}$. No marked abnormalities were found externally. The heart weighed $104.3 \mathrm{~g}$ and contained blood, with $15 \mathrm{ml}$ in the right atrium and 5 $\mathrm{ml}$ in the left atrium. A volume of $50 \mathrm{ml}$ of yellowishclear pericardial fluid containing fibrin deposits was also found. Other organs showed marked congestion without any abnormalities. A histological examination was performed, and the bottom and outlet of the right ventricle, anterior wall, posterior wall, septum, and outlet of the left ventricle were examined. Minor necrosis and degeneration of myocardial cells were observed sometimes in tissue sections, with a lot of lymphocytic infiltration and a few areas of neutrophilic infiltration in the interstitial spaces in each location. However, these findings were marked, especially in four locations in the left ventricle (Figure 1a). No bacteria were detected by a blood culture. Toxicologically, neither alcohol nor other illicit drugs were found in the blood or urine. A viral examination was not performed because of the limited amount of blood. Finally, she was diagnosed as dying from acute fulminant myocarditis.

\section{Case 2}

A healthy 8-year-old boy had suffered from general fatigue with a body temperature of $39.6{ }^{\circ} \mathrm{C}$. The next day after appearance of these symptoms, his general condition did not improve and a temperature of $38.6{ }^{\circ} \mathrm{C}$ persisted. At noon, he suddenly deteriorated and was immediately transferred to the hospital. At arrival to the hospital, he suffered from ventricular tachycardia. Although a resuscitation attempt was performed, he was soon pronounced dead. A forensic autopsy was performed the next day. His height was $122 \mathrm{~cm}$ and body weight was $22.4 \mathrm{~kg}$. No external abnormalities were found. The pericardial cavity contained $12 \mathrm{ml}$ of yellowish-clear fluid with fibrin deposits. A volume of $100 \mathrm{ml}$ of dark red blood was found in the heart cavities. The heart weighted $134.5 \mathrm{~g}$ and showed petechial hemorrhage on the surface of the visceral pericardium, but it was otherwise normal. Histologically, myocardial cells with minor necrosis and degeneration were observed sometimes in tissue sections. There was also a lot of lymphocytic infiltration and a few areas of neutrophilic infiltration in the interstitial spaces of the bottom and outlet of the right ventricle, anterior wall, posterior wall, septum, and outlet of the left ventricle (Fig. 1b). The histological features were similar for six locations. A serological examination did not show adenovirus,

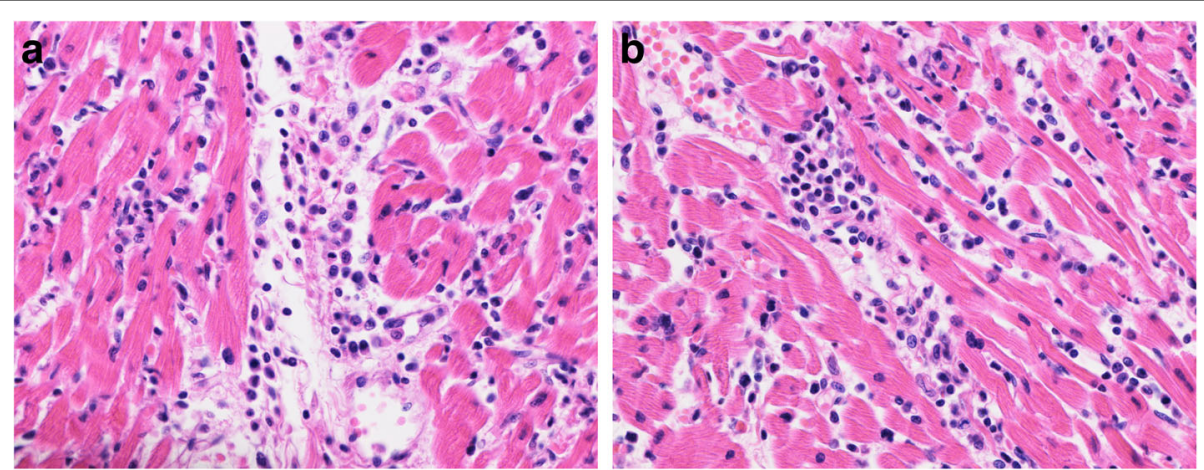

Fig. 1 Histopathological findings of the left ventricle in case 1 (a) and case 2 (b). In myocardial cells of both cases, myocardial cells with minor necrosis and degeneration were observed sometimes in tissue sections, with a lot of lymphocytic infiltration and a few areas of neutrophilic infiltration in the interstitial spaces (magnification, $\times 400$ ) 
influenza A or B, coxsackie A, rotavirus, or respiratory syncytial viruses. Toxicologically, except for acetaminophen and lidocaine, which were used for medical intervention, no drugs and alcohol were detected from the blood. Finally, he was diagnosed with acute fulminant myocarditis.

\section{Immunohistochemistry}

Immunohistochemical staining for complement C9 (CC9) and sirtuin 1 (SIRT1) was performed. We prepared 5- $\mu \mathrm{m}$ paraffin sections of the heart in the two patients by dewaxing, rehydrating, and treating with $0.3 \%$ $\mathrm{H}_{2} \mathrm{O}_{2}$ for 30 min to block endogenous peroxidase. For antigen retrieval, the sections were autoclave-treated in citrate buffer at $\mathrm{pH} 6.0$ for $10 \mathrm{~min}$ and allowed to cool for $30 \mathrm{~min}$. The sections were incubated at room temperature with $10 \%$ normal rabbit serum or $10 \%$ normal goat serum (Nichirei Co., Ltd., Tokyo, Japan) for 10 min. A mouse monoclonal antibody against CC9 (clone 10A6, 1:2000 dilution; MAB9622; Abnova, Taipei City, Taiwan) or a rabbit monoclonal antibody against SIRT1 (clone E104, 1:2000 dilution; NB110-57573; Novus Biologicals, CO, USA) was then applied with incubation overnight at $4{ }^{\circ} \mathrm{C}$. Indirect immunostaining was achieved using the streptavidin-biotin-peroxidase technique. Peroxidase was developed using a diaminobenzidine kit (Peroxidase Stain DAB Kit [Brown Stain]; Nacalai Tesque, Kyoto, Japan). As a negative control, the heart of a child who died in a traffic accident was used. The sections were also lightly counterstained with hematoxylin.

For the six locations of the heart, CC9-positive staining was observed in the cytoplasm. However, these stained regions did not correspond to abnormalities of HE staining. The positive areas corresponded to those of strong accumulation of lymphocytes. SIRT1-positive regions were found for most of the cytoplasm of myocardial cells, but SIRT1 staining was negative in CC9-positive regions (Fig. 2). The CC9positive regions were more marked observed in case 2 than in case 1 . In case 1, the CC9-positive region was marked in the septum and outlet of the left ventricle; in case 2, marked in the septum and posterior wall of the left ventricle.

\section{Conclusions}

In our two cases, the patients suddenly died with short clinical courses. The cause of death was determined by forensic autopsies. Myocarditis is found as a potential cause of death in $3.7 \%$ of sudden infant death syndrome cases (Grasmeyer and Madea 2015). As shown in our cases, performing forensic autopsies for unexpected death in children is important (Weber et al. 2008).

Generally, postmortem diagnosis of myocarditis is based on necrosis and/or degeneration of myocytes and adjacent inflammatory infiltrates (Aretz et al. 1987; Aretz 1987). However, histopathological diagnosis by routine
HE staining remains difficult for some sudden death cases, especially for fulminant cases with short clinical courses. Our two patients showed remarkably similar clinical presentations. The pathological findings with $\mathrm{HE}$ staining also showed similar results of degeneration and necrosis of myocytes with dense lymphocytic infiltration in the interstitial spaces.

For sudden death by fulminant myocarditis, necrosis/degeneration of myocardial cells is not obvious in HEstained specimens. Several types of immunohistochemical staining are applied to acute myocarditis for detecting changes in . Expression of tumor necrosis factor- $\alpha$ (TNF$\alpha$ ) has been examined in the myocardium in human myocarditis (Jibiki et al. 2000). TNF- $\alpha$ is mainly localized in cardiac myocytes and blood vessels and not in infiltrated mononuclear cells. Although TNF- $\alpha$ has multiple actions that mediate the pathogenic processes of cancer, septic shock, and inflammation, the authors speculate that expression of TNF- $\alpha$ in fatal human myocarditis may act as a myocardial depressant. Additionally, immunostaining of tenascin-C has been applied for human acute myocarditis cases (Morimoto et al. 2005; Imanaka-Yoshida et al. 2002). Positive staining for tenascin- $\mathrm{C}$ is localized in the vicinity of damaged myocardial cells and it reflects disease activity. The authors consider that although expression of tenascin-C is not a specific finding for myocarditis, it is associated with injury and inflammation caused by various pathogeneses.

Recently, immunohistochemical staining of the heart has been applied for sudden death cases and morphological changes in acute death have been evaluated. CC9 is useful for detecting acute myocardial damage. When abnormalities are not detected in HE staining in acute myocardial infarction within $6 \mathrm{~h}$ of onset, positive findings of CC9 are observed (Jasra et al. 2012). Furthermore, SIRT1, which modulates cellular adaptation to hypoxia by targeting hypoxia-inducible factor $\alpha$, is also useful for detecting damaged myocytes. SIRT1 is highly expressed in the normal heart and regulates a wide array of cellular process and cardiac electrical activity, and plays a major role in progression of heart failure (Vikram et al. 2017; Tanno et al. 2012). With regard to sudden death due to ischemic heart disease, we barely had obtained typical pathological changes because of the short survival period. However, CC9-positive and SIRT1negative findings show acute damage of myocardial cells (Morita et al. 2015a; Morita et al. 2015b). In this study, we confirmed that this immunohistochemical approach is useful for detecting damaged myocytes, even for sudden death by myocarditis. In this approach, because damaged myocardial cells are more obvious than with other immunohistochemical stains in acute myocarditis, we can easily understand the reason for sudden cardiac arrest. Although CC9 or SIRT1 expression is not a 

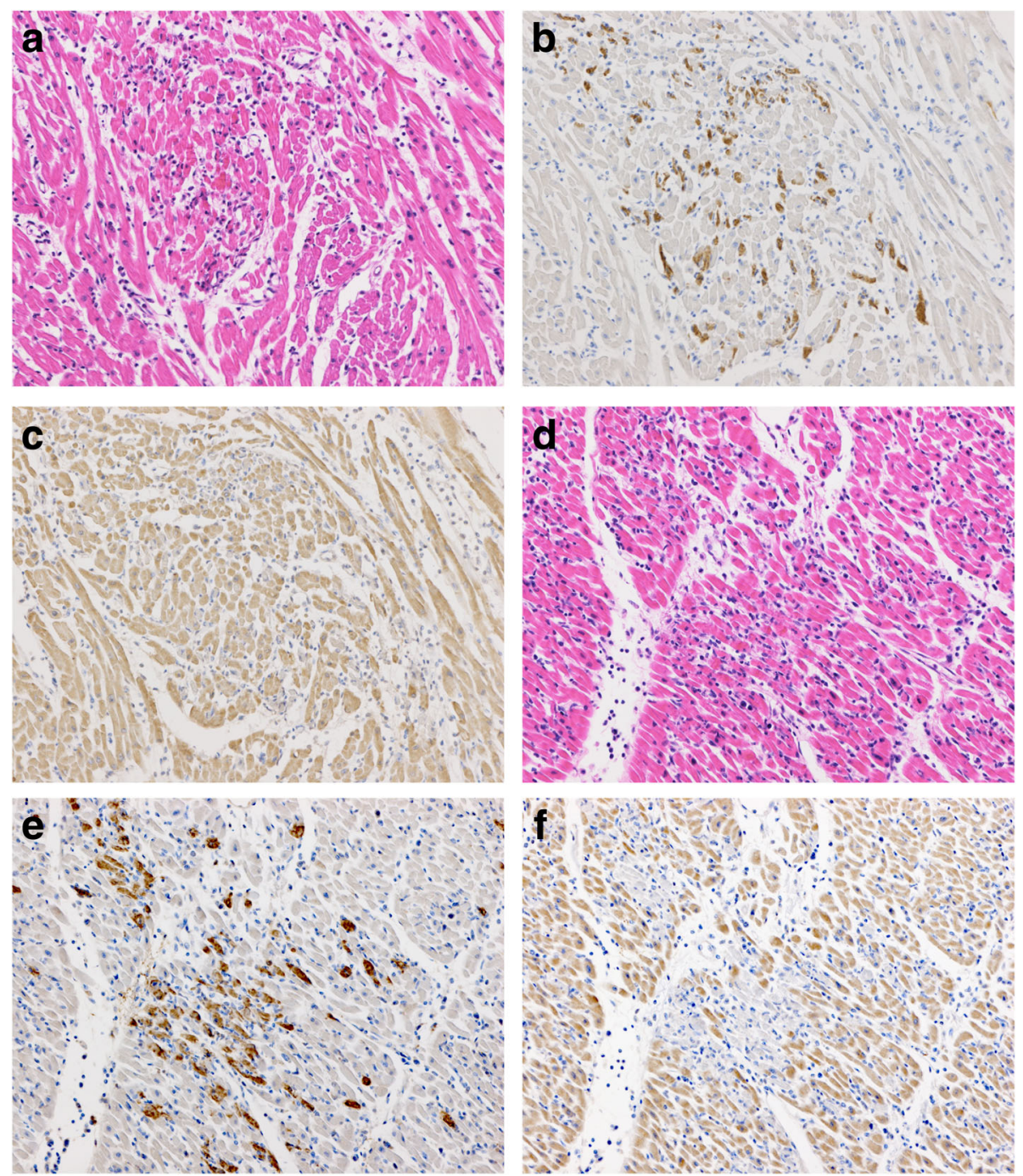

Fig. 2 Images of immunohistochemical staining in myocardial cells in case 1 (a-c) and case 2 (d-f). a, d Hematoxylin and eosin staining. b, e Immunohistochemistry for Complement C9. c, f Immunohistochemistry for Sirtuin I (magnification, $\times 200$ )

specific finding for myocarditis, immunohistochemistry for CC9 and SIRT1 might become a new tool for evaluating damage of myocardial cells of fulminant acute myocarditis. As a limitation, number of cases was not enough to recommend these immunohistochemical stains for fulminant myocarditis. However, authors believe this study was a potentially important prelude to further studies of the utility of these immunohistochemical stains. In the future, this immunohistochemical approach should be performed for other sudden death cases of myocarditis to validate our findings.

\section{Abbreviations}

HE: Hematoxylin and eosin; CC9: Complement C9; SIRT1: Sirtuin 1; TNFa: Tumor necrosis factor-a

\section{Authors' contributions}

ATU and MH performed the autopsies and drafted the manuscript; TM and YH examined the clinical course of patients; ATU performed pathological examination; $\mathrm{MH}$ reviewed the work critically for important intellectual content; MN performed histological analysis; TN drafted the figures and the manuscript; TM and YH acquired and analyzed the data. The authors read and approved the final manuscript.

\section{Funding}

This research was not financially supported by any organization.

\section{Availability of data and materials}

The datasets used and/or analyzed during the current study are available from the corresponding author on reasonable request.

Ethics approval and consent to participate

This study was approved as reference number R2014-010 by Shiga University of Medical Science Research Ethics Committee.

Consent for publication

Written informed consent to publish was obtained from each father. 


\section{Competing interests}

The authors declare that they have no competing interests.

\section{Author details}

'Department of Legal Medicine, Shiga University of Medical Science, Tsukinowa, Seta, Otsu, Shiga 520-2192, Japan. ${ }^{2}$ Department of Pediatrics, Otsu Red Cross Hospital, 1-1-35, Nagara, Otsu, Shiga 520-8511, Japan.

Received: 1 June 2020 Accepted: 12 November 2020

Published online: 21 November 2020

\section{References}

Aretz HT (1987) Myocarditis: the Dallas criteria. Hum Pathol 18:619-624

Aretz HT, Billingham ME, Edwards WD, Factor SM, Fallon JT, Fenoglio JJ, Olsen EG, Schoen FJ (1987) Myocarditis. A histopathologic definition and classification. Am J Cardiovasc Pathol 1:3-14

Dancea AB (2001) Myocarditis in infants and children: A review for the paediatrician. Paediatr Child Health 6:543-545

Fuse K, Kodama M, Okura Y, Ito M, Hirono S, Kato K, Hanawa H, Aizawa Y (2000) Predictors of Disease Course in Patients With Acute Myocarditis. Circulation 102:2829-2835

Grasmeyer S, Madea B (2015) Immunohistochemical diagnosis of myocarditis on (infantile) autopsy material: Does it improve the diagnosis? Forensic Sci Med Pathol 11:168-176. https://doi.org/10.1007/s12024-015-9675-7

Imanaka-Yoshida K, Hiroe M, Yasutomi Y, Toyozaki T, Tsuchiya T, Noda N, Maki T, Nishikawa T, Sakakura T, Yoshida T (2002) Tenascin-C is a useful marker for disease activity in myocarditis. J Pathol 197:388-394. https://doi.org/10.1002/ path. 1131

Jasra SK, Badian C, Macri I, Ra P (2012) Recognition of Early Myocardial Infarction by Immunohistochemical Staining with Cardiac Troponin-I and Complement C9. J Forensic Sci 57:1595-1600. https://doi.org/10.1111/j.1556-4029.2012. 02172.x

Jibiki T, Terai M, Tateno S, Toyozaki T, Horie H, Nakajima H, Niwa K, Niimi H (2000) Expression of tumor necrosis factor-a protein in the myocardium in fatal myocarditis. Pediatr Int 42:43-47

Kamiyama H (2016) Outcome-based clinical training on myocarditis for physicians from residents to board-certiied pediatric cardiologists. Pediatr Cardiol Card Surg 32:365-378. https://doi.org/10.9794/jspccs.32.365

Matsuura H, Ichida F, Saji T, Ogawa S, Waki K, Kaneko M, Tahara M, Soga T, Ono Y, Yasukochi S (2016) Clinical features of acute and fulminant myocarditis in children - 2nd Nationwide Survey by Japanese Society of Pediatric Cardiology and Cardiac Surgery. Circ J 80:2362-2368. https://doi.org/10.1253/ circj.cj-16-0234

Morimoto SI, Imanaka-Yoshida K, Hiramitsu S, Kato S, Ohtsuki M, Uemura A, Kato Y, Nishikawa T, Toyozaki T, Hishida H, Yoshida T, Hiroe M (2005) Diagnostic utility of tenascin-C for evaluation of the activity of human acute myocarditis. J Pathol 205:460-467. https://doi.org/10.1002/path.1730

Morita S, Furukawa S, Nishi K (2015a) Classification of contraction bands using immunohistochemistry. Am J Forensic Med Pathol 36:23-26. https://doi.org/ 10.1097/PAF.0000000000000124

Morita S, Furukawa S, Nishi K (2015b) Immunohistochemical evaluation of hypoxia markers in the myocardium. Aust J Forensic Sci 47:138-146. https:// doi.org/10.1080/00450618.2014.906653

Tanno M, Kuno A, Horio Y, Miura T (2012) Emerging beneficial roles of sirtuins in heart failure. Basic Res Cardiol 107:1-14. https://doi.org/10.1007/s00395-0120273-5

Vikram A, Lewarchik CM, Yoon JY, Naqvi A, Kumar S, Morgan GM, Jacobs JS, Li Q, Kim YR, Kassan M, Liu J, Gabani M, Kumar A, Mehdi H, Zhu X, Guan X, Kutschke W, Zhang X, Boudreau RL, Dai S, Matasic DS, Jung SB, Margulies KB, Kumar V, Bachschmid MM, London B, Irani K (2017) Sirtuin 1 regulates cardiac electrical activity by deacetylating the cardiac sodium channel. Nat Med 23:361-370. https://doi.org/10.1038/nm.4284

Weber MA, Ashworth MT, Risdon RA, Malone M, Burch M, Sebire NJ (2008) Clinicopathological features of paediatric deaths due to myocarditis: An autopsy series. Arch Dis Child 93:594-598. https://doi.org/10.1136/adc.2007. 128686

\section{Publisher's Note}

Springer Nature remains neutral with regard to jurisdictional claims in published maps and institutional affiliations.

\section{Submit your manuscript to a SpringerOpen ${ }^{\circ}$ journal and benefit from:}

- Convenient online submission

- Rigorous peer review

- Open access: articles freely available online

- High visibility within the field

- Retaining the copyright to your article

Submit your next manuscript at $\boldsymbol{\nabla}$ springeropen.com 